\title{
The matrix reloaded: Which pill to take to attenuate thoracic aortic aneurysm development?
}

\author{
Edward Buratto, MBBS, Xin Tao Ye, BBiomed, and Igor E. Konstantinov, MD, PhD, FRACS
}

\footnotetext{
From the Department of Cardiothoracic Surgery, The Royal Children's Hospital, University of Melbourne, Murdoch Children's Research Institute, Melbourne, Australia.

Disclosures: Authors have nothing to disclose with regard to commercial support.

Received for publication Oct 26, 2016; accepted for publication Oct 27, 2016; available ahead of print Dec 10 , 2016.

Address for reprints: Igor E. Konstantinov, MD, PhD, FRACS, Royal Children's Hospital, Flemington Rd, Parkville, VIC 3029, Australia (E-mail: igor.konstantinov@rch.org.au).

J Thorac Cardiovasc Surg 2017;153:547-8

$0022-5223 / \$ 36.00$

Crown Copyright (c) 2016 Published by Elsevier Inc. on behalf of The American Association for Thoracic Surgery http://dx.doi.org/10.1016/j.jtcvs.2016.10.072
}

The matrix of the aortic wall has been a topic of feverish research activity for decades. Medial degeneration of the aortic wall is a key feature of the development of thoracic aortic aneurysms (TAAs), and matrix metalloproteinases (MMPs) are major molecular mediators of TAA formation. ${ }^{1,2}$ MMPs would therefore seem an obvious target for therapeutic intervention to prevent progression of TAAs. So far, only nonspecific MMP inhibitors, tetracyclines and statins, have been studied clinically in an attempt to reduce progression of the aortic aneurysms. ${ }^{3,4}$ Selective therapeutic modification of MMP activity has remained elusive.

A novel study by Ikonomidis and colleagues ${ }^{5}$ published in this issue of the Journal has revisited matrix remodeling as a target for new therapies, and it suggests that targeted inhibition of membrane type 1 (MT1) MMP (Figure 1) may attenuate TAA development. Ikonomidis and colleagues $^{5}$ demonstrated that phosphorylation of MT1MMP caused its internalization and thus prevented MMP-2 activation. Activation of protein kinase $\mathrm{C}-\delta$ by phorbol 12-myristate 13-acetate caused this internalization of MT1-MMP from the cellular membrane to endosomes. This change was associated with a decrease in MMP-2 activity. Yet in a somewhat surprising and subtle way it also resulted in increased phosphorylation of Smad2, a component of the transforming growth factor (TGF) $\beta$ pathway. It has previously been shown that TGF- $\beta$ may activate Smad family proteins and increase production of MMP-9, which in turn causes matrix degradation. ${ }^{6}$ Furthermore, they demonstrated that a protein kinase $\mathrm{C}-\delta$ inhibitor, Röttlerin, could prevent endosomal translocation of MT1-MMP and thus prevent its downstream effects. Normal aortic fibroblasts treated with phorbol 12-myristate 13-acetate displayed reduced MMP-2 activation and increased phosphorylation of Smad2. Both these effects were inhibited by pretreatment with Röttlerin. The activities of TGF- $\beta$ and MMP-9, however, were not assessed. It is therefore not clear whether the effect of Smad2

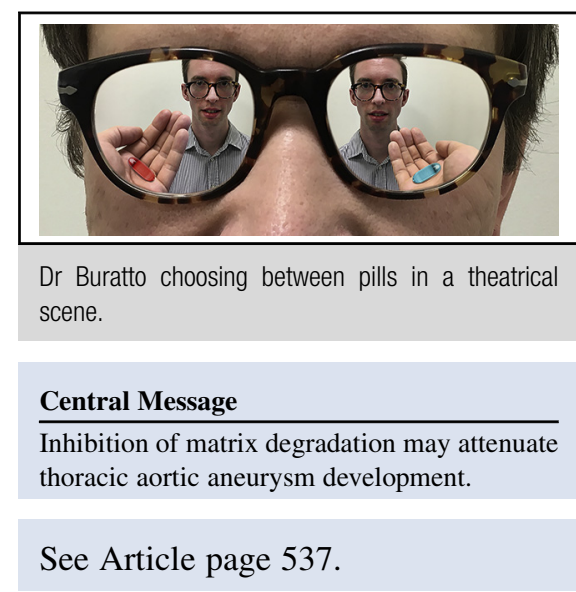

phosphorylation on the downstream pathway is significant Smad2, Smad3, and Smad4 proteins would still have to form a complex that would translocate into the nucleus to stimulate gene expression of MMP-9. Will MMP-9 production be lost in translation? It remains unclear how "deep the rabbit hole goes" and whether the observed isolated increase in Smad2 phosphorylation will have any impact on TGF- $\beta$ signaling. One cannot help wondering where this pathway would lead. This insightful attempt to unveil the mystery of matrix degradation, as often happens in clinical surgery, gives somewhat contradictory results and raises more questions than it answers. How will these pathways balance themselves to affect matrix degradation? Is inhibition of MT1-MMP phosphorylation protective or harmful? Although it appears from the novel finding of the study of Ikonomidis and colleagues ${ }^{5}$ that targeting MT1-MMP activity may indeed constitute a therapeutic strategy, whether this activity should be inhibited or activated is yet to be seen. So, to activate or to inhibit? One is left in suspense by this unanswered question. Yet it seems that Ikonomidis and colleagues ${ }^{5}$ have come very close in their pioneering effort to providing the answer. The answer appears to be very close. It would require evaluation of TGF- $\beta$ pathway and its effect on the matrix after MT1-MMP phosphorylation. In the words of a movie character, "The answer is out there and it is looking for you, and it will find you, if you want it to."

Nonetheless, the unique and strong findings of this study have demonstrated that MT1-MMP is elevated in clinical TAA specimens and that phosphorylation of MT1-MMP causes its intracellular localization and decrease in MMP-2 activation. This is an important step forward in 


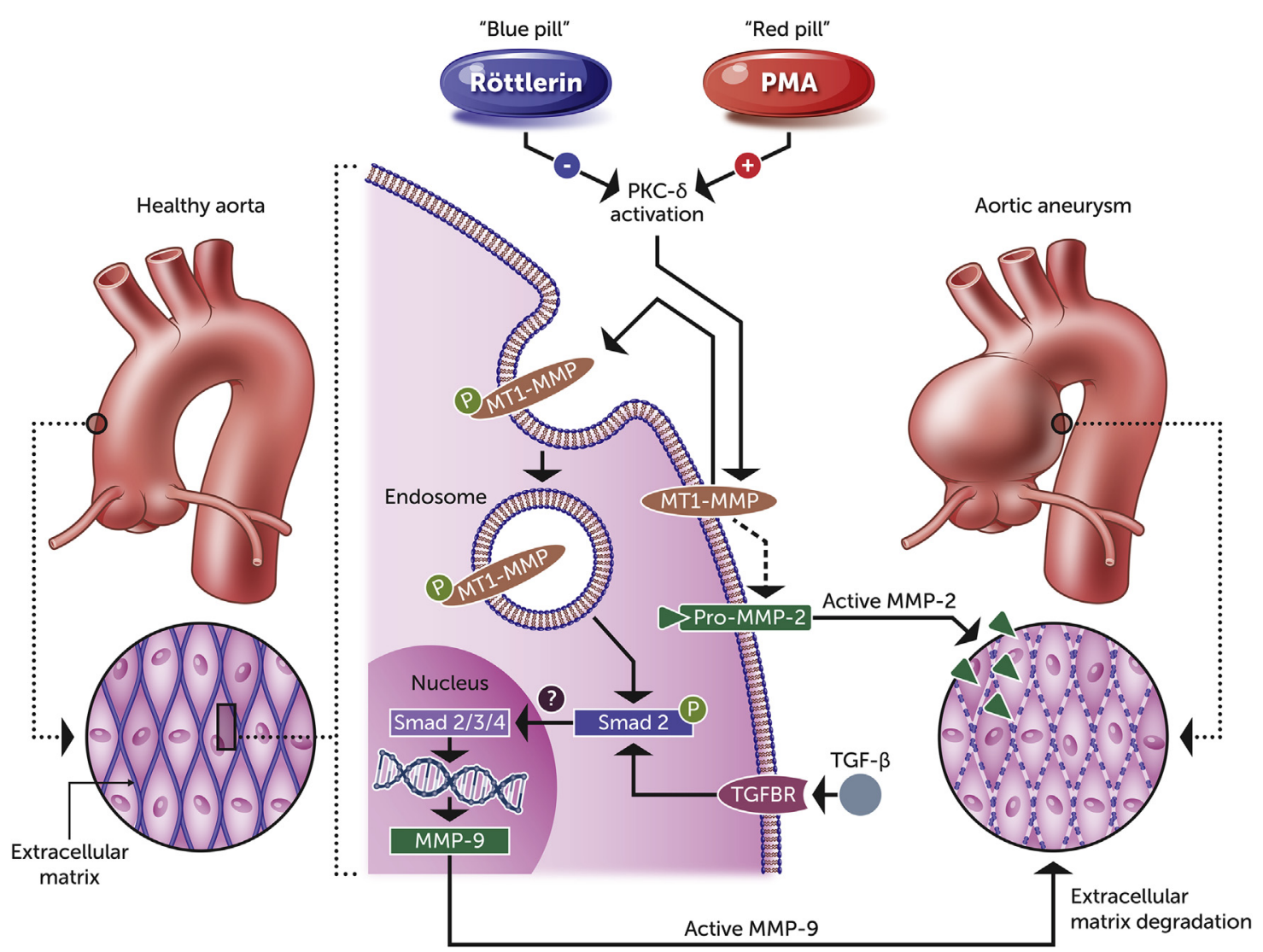

FIGURE 1. Membrane type $1(M T 1)$ matrix metalloproteinase $(M M P)$ internalization and its effects on the aortic extracellular matrix. PMA, Phorbol 12-myristate 13-acetate; $P K C$, protein kinase C; $P$, phosphorylation; $T G F$, transforming growth factor; TGFBR, transforming growth factor $\beta$ receptor.

our understanding of molecular mechanisms of the TAA development.

Although the feasibility of medical intervention to prevent matrix degradation remains unclear, this type of basic surgical research may help to discover "how deep the rabbit hole goes" and lead to important therapeutic applications. The alternative is to "remain in the current reality," steadily convinced that no medical intervention is possible to attenuate the development of this life-threatening surgical disease. The latter is not what the inquisitive mind of an academic surgeon does!

\section{References}

1. Hiratzka LF, Bakris GL, Beckman JA, Bersin RM, Carr VF, Casey DE Jr, et al; American College of Cardiology Foundation/American Heart Association Task Force on Practice Guidelines; American Association for Thoracic Surgery; American College of Radiology; American Stroke Association; Society of Cardiovascular Anesthesiologists; Society for Cardiovascular Angiography and Interventions; Society of Interventional Radiology; Society of Thoracic Sur- geons; Society for Vascular Medicine. 2010 ACCF/AHA/AATS/ACR/ASA/ SCA/SCAI/SIR/STS/SVM Guidelines for the diagnosis and management of patients with thoracic aortic disease. A Report of the American College of Cardiology Foundation/American Heart Association Task Force on Practice Guidelines, American Association for Thoracic Surgery, American College of Radiology, American Stroke Association, Society of Cardiovascular Anesthesiologists, Society for Cardiovascular Angiography and Interventions, Society of Interventional Radiology, Society of Thoracic Surgeons, and Society for Vascular Medicine. J Am Coll Cardiol. 2010;55:e27-129. Erratum in: J Am Coll Cardiol. 2013;62:1039-40.

2. Cifani N, Proietta M, Tritapepe L, Di Gioia C, Ferri L, Taurino M, et al. Stanford-A acute aortic dissection, inflammation, and metalloproteinases: a review. Ann Med. 2015;47:441-6.

3. Braverman AC. Medical management of thoracic aortic aneurysm disease. J Thorac Cardiovasc Surg. 2013;145(3 Suppl):S2-6.

4. Coussens LM, Fingleton B, Matrisian LM. Matrix metalloproteinase inhibitors and cancer: trials and tribulations. Science. 2002;295:2387-92.

5. Ikonomidis JS, Nadeau EK, Akerman AW, Stroud RE, Mukherjee R, Jones JA. Regulation of membrane type-1 matrix metalloproteinase activity and intracellular localization in clinical thoracic aortic aneurysms. J Thorac Cardiovasc Surg. 2017; 153:537-46.

6. Wu D, Shen YH, Russell L, Coselli JS, LeMaire SA. Molecular mechanisms of thoracic aortic dissection. J Surg Res. 2013;184:907-24. 